\title{
OUTROS TEMAS
}

\section{SOBRE A TUTELA DOS CORPOS INFANTIS NA ROTINA ALIMENTAR DA CRECHE}

ANA CRISTINA RICHTER ALEXANDRE FERNANDEZ VAZ

\section{RESUMO}

O trabalho trata do tema da alimentação na rotina de uma instituição de atendimento à pequena infância, focalizando dados de uma pesquisa de abordagem etnográfica. Os resultados revelam que os momentos de alimentação se inscrevem em um contexto no qual o corpo aparece como protagonista de processos disciplinares, direcionados à civilização da conduta de cada indivíduo em particular, e de controle, sustentados por saberes que se apoiam no impulso pela sobrevalorização da sobrevivência biológica, deixando-a "mais sadia". Trata-se de saberes que atuam sobre a redução somática à mera naturalidade do consumo do animal laborans. 


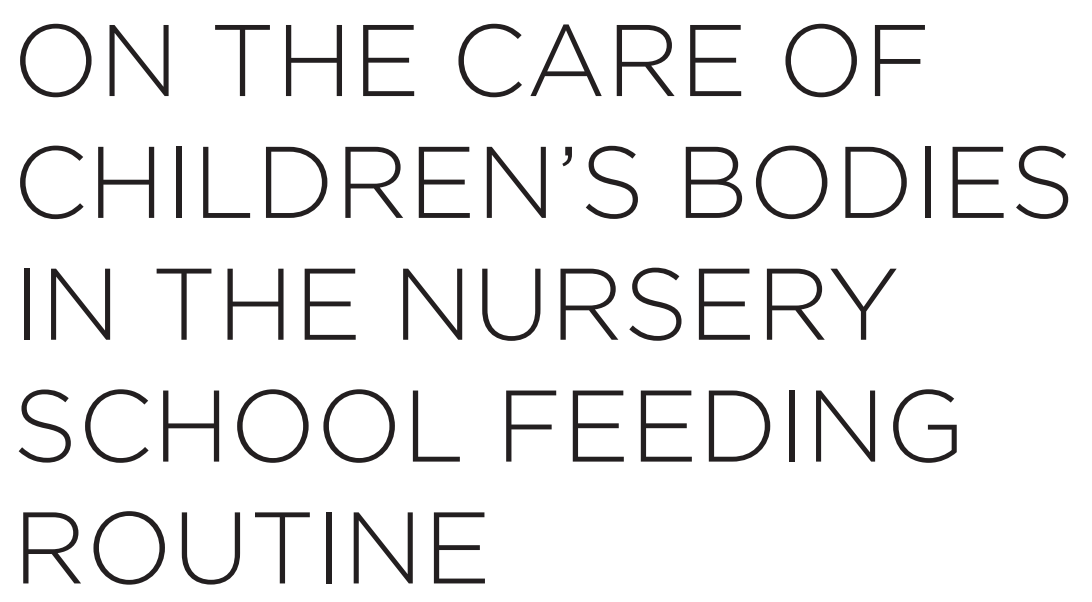

ANA CRISTINA RICHTER ALEXANDRE FERNANDEZ VAZ

\section{ABSTRACT}

This article touches upon the feeding routine within daycare institutions; the data was collected via an ethnographic approach. The results reveal that feeding times fall within a context in which the body is the primary aspect of disciplinary processes, directed at civilizing and controlling the conduct of each individual based on an over-emphasized, biological impulse of survival to maintain the body's "healthiness". This belief sees the human body as merely a biological instrument of the natural act of consumption. 
O TRATARMOS DAS PRÁTICAS alimentares na rotina de uma instituição de atendimento à pequena infância, consideramos sua vinculação com diversos discursos, concepções e práticas presentes na sociedade, que ultrapassam a questão da comensalidade e, explícita ou silenciosamente, adentram os ambientes educacionais, favorecendo a circulação de saberes que ali são trabalhados, interpretados, recriados.

Os saberes sobre a alimentação são tratados por especialistas, veiculados e discutidos em programas televisivos, propalados nas revistas, em colunas de jornais. Atletas, atores e modelos também contribuem para essa divulgação, participando de campanhas que visam incitar à saúde e que convergem para políticas públicas, tais como a Política Nacional de Alimentação e Nutrição - PNAN -, a Política Nacional de Promoção da Saúde PNPS -, o Sistema de Vigilância Alimentar e Nutricional - Sisvan -, entre outros programas e estratégias de saúde pública, direcionados ao combate de déficits nutricionais. Essas estratégias procuram reforçar a resistência dos organismos, protegê-los contra doenças infecciosas, combater a obesidade, as diabetes, a desnutrição e outros males que assolam a população, por meio da garantia da oferta de alimentos adequados à nutrição. O fio condutor dessas políticas é o direito humano à alimentação e à segurança alimentar nutricional (BRASL, 2003).

Também o Ministério da Educação, entre outros órgãos, se faz presente na concretização das políticas de alimentação, ao agenciar a implementação de medidas preconizadas pelo documento supracitado, preparando material educativo, incentivando os escolares a práticas alimentares e nutricionais saudáveis, avaliando a merenda escolar e seu impacto sobre o 
crescimento e desenvolvimento das crianças, entre outros aspectos (BrasiL, 2003).

Todo esse investimento em torno da alimentação se inscreve no contexto dos inalienáveis direitos humanos, "garantidos" pelo Estado soberano que se encarrega da gestão da vida da espécie e se identifica com a vocação dominante da formação e da tutela do corpo popular (Agamben, 2004). Nesse contexto, a consolidação do Estado, que se estrutura para garantir os direitos do homem (do cidadão), se concretiza, paradoxalmente, mediante a hipervalorização da vida biológica ou da conservação da espécie - capturada pelos dispositivos de uma política convertida em biopolítica.

Sua efetividade, respaldada pelo pensamento e pelas práticas médico-higienistas e pelo aparato jurídico, é garantida pelo exercício de biopoderes locais que regem a saúde, a higiene, a sexualidade, a alimentação etc.; e se insere em diferentes espaços sociais, entre eles, os ambientes educacionais, territórios e tempos em que o corpo alcança a posição de protagonista nos processos pedagógicos-disciplinares, mas, principalmente, de controle. Esses processos delimitam a constituição de sujeitos e, ao mesmo tempo, a composição de uma população.

Considerando o quadro descrito e que as práticas corporais contribuem fortemente na (con)formação de comportamentos e subjetividades, este texto discute o tema da alimentação como componente da rotina diária de uma instituição de atendimento à pequena infância e, mais especificamente, dos seus momentos de alimentação, entendidos como uma estação da educação do corpo que encontra na instituição um lugar destacado.

O texto, com base em dados de uma pesquisa de abordagem etnográfica, objetivou inventariar momentos e espaços da educação do corpo, efetivada em uma creche da Rede Pública Municipal de Ensino de uma cidade do sul do Brasil, composta por 38 profissionais que atendem 180 crianças entre 0 e 6 anos de idade. Por meio de análise documental, entrevistas e um longo período de imersão no campo, tratamos dos dispositivos pedagógicos que transpassam o corpo, observando o modo pelo qual operam e se organizam no interior da instituição, considerando os momentos (sugeridos pelos Referenciais Curriculares Nacionais para Educação Infantil) que compõem a Rotina institucional: Entrada, Saída, Alimentação, Sono, Atividade Orientada, Higiene, Parque e, no caso da creche em questão, os momentos de Educação Física ${ }^{1}$.

Organizamos o texto de forma a, primeiro, caracterizar brevemente os momentos de alimentação e descrever a configuração do espaço reservado às práticas alimentares da/na creche. A seguir procuramos retratar alguns elementos que nos levam a identificar a Rotina como subordinada aos momentos de alimentação, sendo esses relacionados às condutas de potencialização da vida meramente biológica e do consumo como norma redutora das crianças e profissionais da instituição à condição de animais laborans².

1

A Rede Municipal de Ensino da localidade em que a pesquisa foi realizada conta, desde 1982, com professores (geralmente professoras) de Educação Física para a educação de crianças de 0 a 6 anos.

2

Hanna Arendt (2002) que analisa as três atividades integrantes da condição humana: o labor, o trabalho e a ação; o trabalho do Homo faber produz um mundo artificial de coisas, cria um mundo comum de significações que possibilitam ao sujeito dar um sentido à própria existência; a ação é a condição da vida política e corresponde à condição humana da pluralidade, a capacidade de agir, de expressar as singularidades, introduzir seus saberes no espaço vivente e começar algo novo, responsabilizando-se pelo mundo público comum. Diferentemente do trabalho e da ação, o labor é uma atividade ligada ao processo biológico. A vida do animal laborans está ligada aos processos vitais, ao que se consome no próprio metabolismo, à conservação física e àquela manutenção e preservação da vida que os homens e os animais comungam. 
Na terceira parte tratamos do cardápio dirigido a uma população específica e que, apoiado na ciência dos nutrientes, acaba por secundarizar fatores de ordem cultural e social que poderiam contar histórias e fazer viver a memória. Na quarta parte do texto destacamos cenas e vozes que ecoam no interior do refeitório, numa tentativa de livrar a infância da "inabilidade", da "incompetência” e, assim, "civilizar" as crianças ao torná-las capazes de gerir o próprio corpo por meio da aprendizagem do autocontrole. Por fim, elaboramos notas finais retomando alguns sentidos em torno das práticas alimentares vivenciadas na creche.

\section{BREVE CARACTERIZAÇÃO DOS MOMENTOS DE ALIMENTAÇÃO}

Para as instituições educacionais destinadas à infância de 0 a $6 \operatorname{anos}^{3}$, a legislação vigente determina que sejam oferecidos às crianças espaços para

Ainda se colocava a nãoescolarização até os 6 anos, diferentemente do atual momento em que ocorre uma transição para os 5 anos como limite para os anos de creche.

As citações entre aspas, quando não referenciadas, foram extraídas de entrevistas e/ou de nosso caderno de campo, sendo geralmente falas de atores da instituição.

Trata-se de encont mensal, realizado no próprio ambiente educacional, em que os/as profissionais se reúnem para estudos discussões administrativopedagógicas por período equivalente a oito horas/aula. momentos de alimentação que atendam às exigências de higiene e segurança, garantindo-lhes "a oferta de alimentos adequados à nutrição, de acordo com cada faixa etária” (VALADÃo, 1998, P. 83). Considerando essas indicações, foi construído na creche estudada, em 2001, um espaço próprio para as práticas alimentares. Segundo dados descritos por uma profissional que administrou a instituição durante onze anos, "antes não tinha refeitório e a alimentação era feita na sala. Aí [todo mundo] passava por todo corredor com roupa suja, com prato de comida. A vigilância sanitária estava sempre ali, implicando porque [...] não podia passar com isso, com aquilo" ${ }^{4}$.

A partir daquele ano, o refeitório passou a ser ocupado diariamente nos momentos de lanche, almoço e jantar pelas crianças, além de reunir as profissionais nos momentos de intervalo e durante as Paradas Pedagógicas 5 . A primeira refeição do dia tem início após a chegada das professoras, às 8 horas. O almoço é servido a partir das 10h30, sendo os bebês alimentados em sua própria sala. À tarde, após o momento de sono, é oferecido o lanche. O jantar é servido das $16 \mathrm{~h} 15$ em diante.

As paredes claras do refeitório abrigam quadros de avisos, um cardápio e uma pirâmide alimentar, instrumento de "orientação nutricional utilizado por profissionais com o objetivo de promover mudanças de hábitos alimentares visando a saúde global do indivíduo e a prevenção de doenças" (Philippi et AL., 1999, P. 66). Esses materiais encontram-se fixados nas proximidades de um pequeno vão de acesso à cozinha, onde travessas e bacias de alimento servidas pelas responsáveis por aquele ambiente, as merendeiras, são retiradas pelas professoras e auxiliares para serem redistribuídas às crianças. Linhas retas sustentam ventiladores de teto e luminárias que, frequentemente, se mantêm desligadas. O espaço contém mesas enormes, uma geladeira antiga, bancos estreitos e compridos em que os pequenos comensais são organizados por grupos etários e orientados pelas professoras e auxiliares que também lhes acompanham durante os outros momentos da Rotina. 
O acesso à cozinha é restrito às merendeiras. Às crianças a entrada não é permitida e os demais atores ingressam naquele espaço rigorosamente asséptico somente em raras ocasiões, sempre vestindo toucas especiais. A entrada na despensa, onde os alimentos são armazenados, é estritamente reservada às merendeiras.

As merendeiras explicam que o trabalho na cozinha é orientado por uma nutricionista, mas também considera os conhecimentos adquiridos nos cursos de manipulação de alimentos, nos quais se aprende "desde tu receberes o alimento até a hora de servi-los”. "A primeira coisa [a ser observada] é o prazo de validade", afirmam. Segundo seus relatos, houve um curso em que “fizeram uma encenação para ver se tu és Maria ou se tu és Joana. Joana é caprichosa e Maria é relaxadona. Ela vai abrir a lata e mete a faca. [...] Pode estar suja. [...] O correto é pegar o abridor; primeiro lavar encima.” E aquilo que Maria “toda erradinha” faz inclui uso de brincos, colares, unhas pintadas e ausência da touca; ela também comete erros ao armazenar alimentos, ao lavar os azulejos, as panelas, o fogão.

Junto a essas diretrizes que normalizam os modos de manipular os alimentos, de vestir-se, de armazenar produtos alimentícios, ao lado daquelas representações gráficas de orientação nutricional, do controle da vigilância sanitária e da legislação que determina as normas para a edificação de espaços para as práticas alimentares, colocam-se as condições necessárias para que a tutela da saúde da população que frequenta a creche se concretize. No registro biopolítico, trata-se de gerir a vida sob a forma de uma lei, de uma legislação universalizada que favoreça a saúde da nação.

\title{
CENTRALIDADE E CENTRALIZAÇÃO DOS MOMENTOS DE ALIMENTAÇÃO NA ROTINA DA CRECHE
}

\begin{abstract}
As crianças brincam livremente sob os cuidados da professora. [...] A auxiliar da turma chega e a professora convida as crianças a se aproximar. Chama-as e, quando ouve o pedido do menino que deseja permanecer no local, informa: "Adulto tem relógio. Por causa do horário do lanche." Faz soar um sino [...] e começa a nomear as crianças que relutam em se aproximar. [...] Após reunir o grupo, explica que há crianças que não escutam; que fica "chamando" e "o horário já terminou." [...]. A auxiliar interrompe e diz: "Estamos atrasados. Agora nós vamos lavar as mãos com cuidado que as tias já lavaram o banheiro e depois vamos lanchar".
\end{abstract}

Ao contrário dos vários outros momentos que organizam a Rotina da creche, os de alimentação jamais são interrompidos. Cessa o brincar, a atividade orientada, o sono e, com frequência, escuta-se: "depois a gente termina”, “depois de comer vocês terminam de assistir ao filme”, “depois de comer a gente vai para o parque”, “dorme logo, senão você vai perder o 
horário do lanche”. Essas interrupções constantes, aliadas ao destaque dado às práticas alimentares nas pautas de reunião e nas conversas de intervalo das professoras ${ }^{6}$, apontam os momentos de alimentação como possíveis piTratam do estabelecimento de condições favoráveis à saúde; das problemáticas sobre quantidade de crianças no refeitório, dieta equilibrada etc lares de estruturação dos demais períodos da Rotina. Ou seja, todas as atividades desenvolvidas no dia a dia da creche colocam-se subordinadas aos momentos de alimentação e devem "correr" de acordo com o ritmo ditado pelos horários de lanche, almoço e jantar, organizados pelas merendeiras.

Não há dúvidas, conforme apontamos anteriormente, sobre a importância da alimentação como tema de debate público no mundo contemporâneo e isso vale não apenas para as creches. A comida tornou-se, como parte das preocupações com o corpo e suas formas, a saúde e seus destinos, "um importante foco de perturbações e estudos" (SAnt'AnNA, 2003, P. 42), um tema a ser comentado pelas revistas ilustradas, pelos programas televisivos, um elemento da cultura do medo que se instala em relação à prevenção de doenças de todos os tipos. Nesse sentido, a alimentação compõe um conjunto de dispositivos de controle sobre o corpo que se estruturam como intervenção racional-mecanicista, científica, atuando sobre a redução somática à mera "naturalidade" do animal laborans. Este, na acepção clássica de Hannah Arendt (2002), é aquele modelo de indivíduo que vive para o consumo imediato (do tempo, da faina, de si mesmo). Como sugere Giorgio Agamben (2004), fortemente alicerçado em Foucault, esse movimento - que é de despolitização, ao reduzir tudo à vida não mais que biológica - se ocupa não apenas do corpo do indivíduo em particular, mas sim se coloca como biopolítica da espécie humana com vistas a manter estados de equilíbrio, de regularidade e, no limite, fazer-viver a população.

Poderíamos supor que essa regulamentação da vida opera na creche, sobretudo, por meio dos momentos de alimentação que se disciplinam pela legislação, que respeitam o cardápio elaborado pela ciência da nutrição e têm como tutoras as merendeiras, personagens principais, deixando em segundo plano o trabalho pedagógico das professoras. Registramos várias situações em nosso diário de campo nas quais as merendeiras abriam as portas das salas e anunciavam: "meninas, o almoço vai demorar um pouco". Noutras ocasiões, assistimos essas profissionais solicitando a alguma criança em passagem pelo corredor que retornasse à sala com a mensagem: "chama para almoçar". Da mesma forma, o lanche realizado pelas professoras, em seu intervalo, é também condicionado pelo trabalho das merendeiras, tal como se pode observar em cena por nós registrada: "a auxiliar avisa a professora que irá tomar seu café, pois não almoçou. Em seguida, retorna e comenta: 'não tem café ainda"”.

Essas cenas evidenciam não somente a centralidade dos momentos de alimentação, mas também o domínio das profissionais responsáveis pelas práticas alimentares sobre os demais atores da instituição, determinando o tempo em que essas práticas devem ocorrer. Tudo isso aparece reforçado por uma dimensão espacial, visto que há territórios, a cozinha e a despensa, que, 
para além das normas fundamentais de higiene, são, praticamente exclusivos e governados por essas profissionais.

A captura da esfera política se expressa na centralidade dos momentos de alimentação e em sua centralização nas mãos das merendeiras. Junto a isso, engendra-se a preocupação constante, por parte dessas profissionais, em atender e observar as recomendações científicas relacionadas à alimentação, aspecto sobre o qual trataremos a seguir.

\section{O CARDÁPIO: INGERIR NUTRIENTES E SEGUIR NORMAS SOCIAIS}

A dieta das crianças é prescrita por profissionais de uma "empresa terceirizada” que, segundo a merendeira, além de realizar a entrega dos mantimentos, “oferece nutricionista”. Há dois cardápios. Um deles atende a primeira e a terceira semanas do mês e o outro às demais. Nos momentos de lanche, achocolatados, leite, bolo, mingau, bolachas e frutas variadas, entre mamão, laranja, banana e maçã, são oferecidos às crianças. Em épocas de colheita, também abacaxi e melancia. No almoço e no jantar serve-se arroz, feijão, macarrão, ensopados, saladas, refogados, ovos, carnes de frango, gado e peixe.

O cardápio é evidenciado nos relatos das merendeiras que destacam que "a nutricionista arruma o cardápio para nós. Ela vem de três em três meses, vê se as crianças estão comendo direitinho [...]". E ainda: "Tá ali no cardápio, a gente faz”. Harmonizado com a ciência dos nutrientes, o cardápio "satisfaz necessidades básicas da faixa etária", proibindo, sancionando, prescrevendo o que se deve comer a partir de fundamentos que visam sustentar o corpo, dar-lhe disposição, evitar a obesidade e as carências alimentares ${ }^{8}$. Esses aspectos são reforçados pelos/as professores a cada instante, quando anunciam aos pequenos que "chuchu é bom para ficarem fortes" ou que é preciso “comer tudo para ter força para brincar no parque” e, também, pelos familiares das crianças quando elogiam o fato de a creche oferecer "alimentação correta" ou "boa alimentação".

Enquanto as merendeiras intervêm de modo a suplementar a vida, os pratos que preparam também contribuem - para além daqueles elementos fundamentais de ordem fisiológico-nutricional que garantem a manutenção da vida e que não devem ser desprezados - para o esquecimento de fatores de ordem social, econômica e cultural que também envolvem as práticas alimentares, a exemplo da impossibilidade de tomar contato, por meio do alimento, com as memórias e tradições ${ }^{9}$ recriando sabores, transformando-os na incorporação do que Walter Benjamin (1993) chamou experiência (Erfahrung). Nessa mesma direção, o cardápio é “emancipado" e privado dos traços regionais da cultura, tal como a tainha, pescado fartamente disponível em determinados períodos anuais na localidade em que a pesquisa foi realizada, mas sempre ausente nas refeições. O cardápio da creche atende àquela legislação que exige a garantia da oferta de alimentos “adequados à nutrição”, mas também contribui para o esquecimento do conjunto de elementos de ordem

Na história das crianças no Brasil, nem sempre houve a presença de um cardápio específico destinado aos pequenos, segundo revela Del Priore (1999); entre os grupos humanos inseridos em um mesmo contexto, as práticas alimentares destinadas às crianças envolveram rituais diversos, sem que se distinguisse alimentação infantil de adulta. Assim que obtivessem a capacidade de morder, as crianças da elite eram iniciadas no cardápio familiar. No caso dos bebês, amas-de-leite se ocupavam da amamentação. Por sua vez, as escravas, de origem africana, amassavam alimentos com as mãos e fortificavam os filhos com feijão e pirão de leite, enquanto as crianças indígenas comiam frutos e outros alimentos mastigados pelas mães. Somente no mundo moderno - quando emerge a particularidade do universo da infância e à criança é conferida uma identidade própria -, o cotidiano dos pequenos passou a ser orientado também por meio de manuais e cardápios exclusivamente preparados para a pequena infância a partir dos saberes da ciência. Isso, num momento histórico em que ganham destaque os discursos voltados à "criação" de uma infância higiênica (Gondra, 2000) e no intuito de transformar a criança no "homem digno do amanhã", o que se supunha contribuir para a melhoria da sociedade e, sobretudo, da espécie.

8

Vale lembrar que a obesidade é uma das grandes preocupações contemporâneas da saúde pública, alvo de estratégias biopolíticas de conformação corporal relacionadas também aos modelos de embelezamento. 9 A localidade em questão foi colonizada por açorianos e madeirenses. A eles juntaram-se imigrantes alemães, italianos, ucranianos, poloneses, africanos, entre outros, trazendo consigo hábitos, costumes e crenças, transformados em lembranças ou esquecimentos; são documentos de uma história na medida em que a rememoramos. 
cultural que contam a história e fazem viver a memória, compondo a experiência.

Esse aspecto ainda aparece relacionado às características dos produtos alimentícios que compõem um cardápio destinado a uma população específica (infantes como condição sociocultural e, além disso, oriundos de famílias de baixa renda), tal como a carne que, segundo a merendeira, "é de segunda”. Parece-nos que o cardápio da creche também funciona como uma espécie de "preparação", ou seja, desde a infância aprende-se a consumir os produtos que o segmento social que frequenta a instituição pode e deve consumir.

A dieta prescrita para essas crianças - ou essa exigência socialmente distribuída - faz com que se constitua um padrão alimentar específico: uma formatação do paladar, uma educação do sentido da gustação. Noutras palavras, ao incorporar o alimento, as crianças são também educadas, ainda que possam a isso resistir, para a incorporação a uma ordem social. Aprendem, moderna de que todos teriam acesso à formação cultural, algo coligado à ideia de indivíduos livres e de uma humanidade sem injustiças, o que se confronta a uma situação "erigida sobre a subsunção do valor de uso ao valor de troca das mercadorias da divisão desigual entre o trabalho manual e espiritual. [...] necessidades básicas tais como as de caráte afetivo, subsumem-se cada vez mais àquelas produzidas de acordo com as regras de consumo. A produção cultural é constituída de forma a não propiciar aquilo que não pode cumprir desde o seu começo: a garantia de uma sociedade racional, livre e igualitária" (Zuin, Pucci, Oliveira, 2000 diante da oferta de locais e produtos que se colocam "à disposição de todos os indivíduos", que seriam "livres" para escolher ${ }^{10}$, por meio do autocontrole, aquilo lhes cabe como comensais.

Por meio da repetição de sabores determinados, introvertem-se as normas de conduta que, a um só tempo, regulamentam uma população e, conforme detalharemos nas próximas páginas potencializam o corpo de cada indivíduo em particular.

\section{ALIMENTAR E CIVILIZAR: LIVRAR A INFÂNCIA DA INABILIDADE}

CENA 1

No refeitório a auxiliar avisa: "Só vou dar o prato para quem estiver sentadinho". Serve duas conchas de arroz em cada prato, acompanhadas de um "Vai passando". [...] Facas e garfos são entregues e, enquanto comem, as crianças batem com os talheres sobre os pratos e sobre a mesa. [...] Três crianças se aproximam da auxiliar e pedem: "Bota mais frango?” Ela serve e comenta: "Mas come todo o arroz". [...] Uma professora caminha com um prato e come. Larga-o e auxilia uma criança. Os ruídos são intensos. Escuta-se um grito, "Vais comer ou ficar de palhaçada?", que se mistura aos berros das crianças. [...] Está escuro e as luzes não foram ligadas. Escuta-se: "Deu!" "Vai sentar". "Deu!" "Come. Vai ficar com fome depois". "Para!" - repetidas vezes. "Para de fazer fofoquinha e vai comer”. "Senta direito”. Desviando a atenção à auxiliar, percebe-se que esta circula com o seu prato na mão. Come em pé, rapidamente. No intervalo entre as garfadas, corta a carne para uma criança, ajeita o prato de outra. A servente aparece e espia o ambiente, enquanto uma professora limpa a mesa com um pano. [...] Uma criança solicita uma faca e a professora, ao alcançar, comenta: “Que adultos (!), comendo de faca”. [...] A merendeira se aproxima e, ao observar o piso e as mesas repletas de alimentos, 
comunica às crianças: "Tudo mocinha grande, rapazinho grande, fazer esta imundície... Onde se viu?”.

\section{CENA 2}

A professora entrega bananas e os pequenos descascam-nas. Quando uma delas termina, a professora diz: "Viu? Ela já descascou”. Um garoto encontra dificuldades diante da fruta e a auxiliar (que descasca maçãs, retira os caroços e pica as frutas) levanta e o auxilia. [...] Noutra mesa, dois meninos solicitam bananas, mas não são atendidos, pois: "Quando estou servindo, vocês tem que saber se tem fome ou não. Agora a professora não vai mais dar".

\section{CENA 3}

Da cozinha uma servente dirige-se a uma criança, dizendo: "Senta, senta [...]”. Uma professora puxa de seu lugar, pelo braço, um menino. Coloca-o sentado à quina da mesa, comunicando que irá "servir de palhaço para os outros”. A auxiliar busca facas e garfos enquanto a professora do grupo serve os alimentos: uma concha de arroz em cada prato, seguido de um "vai passando". Em seguida, com o corpo curvado sobre a mesa, oferece chuchu àqueles que desejarem. [...] A auxiliar comenta: "Chuchu é bom para eles ficarem fortes”. Pelo chão, arroz espalhado. [...] Um menino come do prato, pois os talheres ainda não foram entregues. Finalmente, após recebê-los, as crianças comem vorazmente. Noutra mesa, crianças que receberam apenas garfos dispõem a comida sobre estes, com auxílio das mãos. Um menino passa a língua na faca e mostra aos colegas. Três deles o imitam. [...] Sobre as mesas e pelo chão, muito arroz espalhado: "Ninguém merece”, diz a professora. [...] "Senta, senta, senta”. "Quem não comer não vai assistir ao vídeo", anuncia outra professora. [...] Uma criança tenta devolver a comida e, antes que conclua uma palavra, é interrompida: "Não quero ouvir o que tu vais dizer. Come".

Em entrevista, uma profissional explica que os momentos de alimentação também visam "trabalhar a autonomia da criança para ela se servir [...]. Para que mais tarde ela possa se virar num grupo maior”. Tanto as cenas descritas, quanto a fala da professora, sugerem um destacado investimento sobre as crianças e suas expressões não civilizadas, numa tentativa de livrá-las, o mais cedo possível, de uma infância que revelará descontroles, desejos, pulsões, enfim, tudo aquilo a que se nos exige renunciar e que expressa uma dimensão não racional, da natureza presente em cada ser humano. Isso também pode ser percebido novamente nas palavras da professora:

A gente está trabalhando com sete crianças que estão agora comendo sozinhas. Tem aquela sujeirada toda ainda. Mas tem criança que não se suja mais, que come tudo bem direitinho. No ano que vem já vão estar craques na comida! Então, são coisas que a gente 
Esse esforço, presente desde o berçário, procura regular as crianças quanto aos gestos e posturas relacionados ao próprio corpo, entre eles, o refinamento dos hábitos à mesa. Esse processo, segundo ensina Norbert Elias (1993), amplia patamares de embaraço e vergonha, o que contribuiria, junto com os mecanismos de autocontrole, para a regulação estável da vida social. Concorrem para isso os elogios e as reprimendas. No primeiro caso, vale destacar o destinado àquele que "descasca rapidamente a fruta". Nessa mesma direção colocam-se os louvores às crianças que fazem uso da faca. Segundo Elias (1993), o manejo da faca envolve inúmeros tabus e proibições ao sublimar e atualizar o instrumento como arma de ataque e de abate de animais, mas também na forma de ameaça à vida, símbolo de morte e de perigo. Talvez possamos pensar que a expressão da professora "que adulto comendo de faca” esteja relacionada ao autocontrole diante de um objeto ameaçador, capaz de ferir o corpo, no limite, tirar a vida, além de representar o "ingresso" no universo civilizado por meio do domínio daquele utensílio. As reprimendas, por sua vez, destinam-se aos desajeitados, à criança que irá “servir de palhaço aos demais”, ou àquelas que são alvo de denúncia na voz da merendeira: "tudo mocinha grande, rapazinho grande, fazer esta imundície... Onde se viu?".

As cenas descritas e as vozes dos/das profissionais parecem mostrar um empenho que se dirige, sobretudo, à conservação da vida que deve ser afastada das condutas "primitivas" ou daquela natureza não racional; a criança deve ser, desde muito cedo, liberada da tutela do adulto para agir mediante o autocontrole que, na fala dos/das profissionais, corresponde à “autonomia”. Esse processo, que é o de domínio e ao mesmo tempo repulsão ao corpo, recebe uma contribuição fundamental dos momentos de alimentação.

A vitória do autocontrole nos gestos e posturas, a abdicação da natureza em favor da civilidade representada pelos adultos na creche - e também pelas crianças que já estão "craques na comida" -, são também o triunfo dos sacrifícios internalizados. O tributo pago pela renúncia, talvez acabe, no entanto, por se revelar nos gestos bruscos, nas ameaças, nos castigos lançados sobre as crianças, toda vez que aqueles não surtem o efeito desejado, ou que estas se rebelam contra a disciplina civilizadora. Lembremos aqui de reflexões de Horkheimer e Adorno, segundo quem as atitudes severas podem estar relacionadas ao reconhecimento de algo da própria natureza dos sujeitos nesses mesmos gestos que são repelidos nos pequenos e que são familiares aos adultos: 
Lembre-se que toda pedagogia se dirige, de uma forma ou de outra, à suplantação da mimesis pela racionalidade, do aconchego que faz o corpo aproximar-se de seu outro pelo cálculo e pela medida (HoRKHeImer, 1996).

Nesses termos, o que é negado, proibido ou simplesmente reprimido - aquilo que se percebe nas crianças e se pretende eliminar - acaba por emergir na forma de mal-estares, humilhações, gestos rudes e palavras ásperas: rastros que não podem ser apagados nesse processo de determinação do autocontrole, de dominação do corpo, de enrijecimento contra a natureza, algo que representa, para Horkheimer e Adorno (1985), a natureza mutilada e esquecida de si mesma.

Se de um lado, o domínio das emoções, a adaptação à norma, a aprendizagem do autocontrole tornam a vida social mais estável, por outro, é preciso lembrar que isso exige um enrijecimento do indivíduo contra si mesmo. Exemplo disso encontra-se na análise que Horkheimer e Adorno (1985) fazem da Odisseia homérica. Ulisses, personagem da narrativa, entendido como o protótipo do sujeito em formação, só consegue retornar à pátria na medida em que controla sua natureza interior: não se deixa levar, de todo, pelo canto das sereias; delicia-se com a melodia, mas, para tanto, mantém-se atado ao mastro do navio, sacrificando seu desejo a fim de conservar-se, de preservar-se da morte, representada pela dissolução que a plena gratificação lhe imputaria. Ele precisa controlar aquele momento de desejo e impulso de assimilação, de fusão, de integração à natureza, restando-lhe organizar os comportamentos, renunciar à gratificação imediata e desviar seu curso a fim de preservar-se.

Os pequenos comensais que frequentam a creche também aprendem a organizar os comportamentos: observamos inúmeras ocasiões em que as crianças ingerem, velozmente, porções que lhe são destinadas, mesmo quando verbalizam não sentir fome; também comem vorazmente quando lhes é dito que somente receberão "mais carne se comerem todo o arroz". Ou seja, diante do "perigo" de não receber mais carne, de perder o momento de parque, de permanecer de castigo, os pequenos entregam-se à repetição das ações que lhes são exigidas, adaptando-se à norma ou "engolindo o que deve ser engolido" a fim de obter uma bonificação, tal como Ulisses que se coloca sob sujeição de amarras exteriores (o mastro do navio), garantindo, sem dissolver-se como sujeito, a parcial gratificação da pulsão.

Se o processo civilizador exige renúncias e sacrifícios, se o controle do corpo é o seu primeiro degrau, e é também ${ }^{11}$ uma ocupação das instituições educativas auxiliar os pequenos no seu curso, esse processo aparece, em diversos momentos da Rotina alimentar da creche, reforçado pela repetição da norma (sobre corpos vivos e sobre a vida, um processo de coletivização, vale dizer) que se institucionaliza por meio do saber científico. Esse movi-

11 Para Adorno (1995, p. 143). "a educação seria impotente e ideológica se ignorasse o objetivo da adaptação e não preparasse os homens para se orientarem no mundo. [...] igualmente questionável se ficasse nisso, produzindo nada além de pessoas bem ajustadas". 
mento parece muitas vezes ser imposto a cada um de modo dolorido, de maneira a construir uma memória marcada pela dor.

Adorno observa que uma educação para a disciplina por meio da dureza personifica-se no aprendente que, ao identificar-se com a figura do adulto, acaba por transformar-se também em agressor: "Ser duro" significa, nesses termos, "indiferença contra a dor em geral". Nesse processo não se diferencia a dor do outro da de si próprio e da dor em geral. "Quem é severo consigo mesmo adquire o direito de ser severo com os outros, vingando-se da dor cujas manifestações precisou ocultar ou reprimir" (ADoRno, 200o, P. 128). Reconhecer esse mecanismo e promover uma educação que não premie a dor e a capacidade de suportá-la são, para Adorno, aspectos que devem ser seriamente considerados no âmbito da educação.

\section{PALAVRAS FINAIS}

As práticas alimentares, os espaços e tempos a elas destinados no cotidiano da creche são tomados, sobretudo, com o propósito de civilizar a conduta dos pequenos, torná-los “craques” no domínio de técnicas e utensílios que conformam os hábitos à mesa. Ao lado disso, os saberes da ciência, a diversidade de produtos e recursos que conduziram e conduzem ao bem-estar e ao progresso, também produziram outros ritmos de vida, outras dinâmicas nas relações, revelando a degradação da experiência nas alterações impostas à percepção. Junto às dietas, aos espaços e tempos de alimentação, colocam-se elementos determinantes na produção de subjetividades, representados pelos hábitos, pelas percepções sensoriais, pela linguagem, como "produtos" do modus vivendi da urbanidade. Nesse contexto as identidades vão se constituindo a partir de exigências técnicas: reações rápidas, percepções imediatas, identificação quase que total com o existente.

Nos ritmos frenéticos do "direito à alimentação" perdem-se, então, outras relações que envolvem a percepção dos sentidos na aproximação com o alimento, representações simbólicas construídas que traduzam a experiência no espaço do refeitório. Tanto crianças quanto professoras encontram dificuldades quando indagadas a respeito dos ingredientes e temperos utilizados na preparação dos pratos, e os pequenos ainda mais, quando se trata de descrever os sabores dos alimentos.

A capacidade e a possibilidade de entregar-se aos alimentos com todos os sentidos, de incorporar a experiência com a comida, ou, como afirma Benjamin (2000, P. 217), de molhar a colher com a língua, beber com os olhos o prato e descobrir que dentro dele "existe neve, flocos derretidos, comida feita de nuvens [...] que tem o dom de saciar suavemente e aos poucos penetrar-te", são esvaziadas. O momento de contato com as linguagens silenciosas, impregnadas de odores, sabores, cores, texturas, prazeres e desprazeres, se perde em meio à administração maquinal de organismos que são abastecidos nessa pseudoatividade (Adorno, 1995) que meramente garante a autoconservação física e, ao mesmo tempo, ensina a, tecnicamente, sujeitar-se. 
Benjamin mostra que a experiência, qualidade fundamental de constituição do sujeito, é atravessada pelo corpo, é "in-corporada” com os cheiros, sabores, tato, que submerge e se entrega com os sentidos não enrijecidos também aos alimentos. No aforismo "A despensa”, escreve:

\begin{abstract}
$\mathrm{Na}$ fresta deixada pela porta entreaberta do armário da despensa, minha mão penetra tal como um amante através da noite. Quando já se sentia ambientada naquela escuridão, ia apalpando o açúcar ou as amêndoas, as passas ou as frutas cristalizadas. E, do mesmo modo que o amante abraça sua amada antes de beijá-la, aquele tatear significava uma entrevista com as guloseimas antes que a boca saboreasse sua doçura. Com que lisonjas entregavam-se à minha mão o mel, os cachos de passas de Corinto e até o arroz! Com que paixão se fazia aquele encontro, uma vez que escapavam à colher! Agradecida e desenfreada, como a garota raptada de sua casa paterna, a compota de morango se entregava mesmo sem o acompanhamento do pãozinho e para ser saboreada ao ar livre, e até a manteiga respondia com ternura à ousadia de um pretendente que avançara até sua alcova de solteira. A mão, esse Don Juan juvenil, em pouco tempo, invadira todos os cantos e recantos, deixando atrás de si camadas e porções escorrendo a virgindade que, sem protestos, se renovava. (2000, P. 87-88)
\end{abstract}

Esse contato traduz outras possibilidades de relação com a comida, em que os sentidos não estejam enrijecidos, revelando não apenas processos de assimilação das comidas que visam avigorar, manter abastecido ou sustentar o organismo, mas também, e sobretudo, admitindo o que o corpo possa comportar como construto simbólico. A alimentação envolve algo mais que a finalidade de nutrir-se e permanecer são. Implica saber do sabor independentemente de seu valor calórico, dos critérios científicos e jargões vinculados à qualidade de vida, remetendo a impressões sentidas, desejos, toques e prazeres quando a comida encontra o corpo, ao mesmo tempo em que está implicada pelas palavras, olhares e gestos levados à criança junto ao que lhe é servido nos momentos de refeição.

Os/as professores se incumbem de cuidados direcionados a cada criança em particular, com o propósito assumido tacitamente de ensinar os pequenos a controlar, de modo "autônomo" (ou autômato), o corpo: um corpo "civilizado", seja no uso apropriado dos talheres, no descascar de uma fruta, ao habituar o paladar a sabores predeterminados ou no "comer sem fazer aquela sujeirada toda”, como nos diz uma professora. Enfim, para que os "menores" não se desviem do cardápio que lhes convêm e para que evitem deixar a presença de restos no terreno em que realizam as práticas alimentares. As merendeiras e os demais atores institucionais se ocupam da população que frequenta a creche com base nas orientações da vigilância sanitária, das políticas nacionais de alimentação e nutrição, da legislação vinculada à 
educação infantil, do cardápio elaborado a partir de recomendações científicas e dos cursos de manipulação de alimentos.

Nas práticas alimentares destinadas aos pequenos comensais, encontramos algumas das relações do processo civilizador com a organização da sociedade contemporânea, com os processos de individuação e totalização ou, ainda, com um projeto social interessado, sobretudo, no corpo (e na) da espécie. Os momentos de alimentação da/na creche parecem revelar algumas formas de circulação de saberes relacionados "uma organização normal e coletiva (e, portanto, política) da vida humana” (AGAMBEN, 2004, P. 142).

A dedicação à saúde por meio da elaboração e consecução do cardápio, a formatação do paladar por meio da incorporação/ingestão de alimentos específicos, a severidade na exigência da formação dos hábitos à mesa, o interesse pelo método, as necessidades básicas calculadas, colocadas em estatísticas e orientadas pela produção de saberes científicos, enfim, tudo aquilo que consistiria em meios provisórios para se chegar a um fim, coloca-se como um fim em si mesmo.

Nesse progresso de "incivilidade" para "civilização", a geração mais nova é, então, conduzida a uma vida sadia, porém, petrificada em caminhos já trilhados; a um governo de si, porém enraizado em um processo de adaptação efetivado de modo severo e dolorido e que tem seu correlato no desenvolvimento de sentimentos que acabam se traduzindo em violências nem sempre tão visíveis, como costuma, aliás, se manifestar a barbárie de nossos dias.

Como já salientamos, é preciso equipar as crianças para orientar-se no mundo, e isso obviamente passa pelos processos de regulação de si e de autocontrole, tributos à vida civilizada. A questão é, no entanto, em que medida esses processos não se tornam um fim em si mesmo e o autocontrole não emerge como domínio exercido por uma razão formalizada e instrumental. Nesse movimento, os alimentos reduzidos ao seu valor calórico e à velocidade do consumo não podem mais compor momentos pedagógicos e lúdicos no interior da instituição. Ao desviar a atenção para todos os momentos, espaços e tempos que compõem o dia a dia nas instituições, talvez possam se desvelar tantos outros caminhos que governam secretamente os corpos, os sentidos e, nesse sentido, "fazer sair o político de sua ocultação" (Agamben, 2004, P. 12), rescindindo a identificação imediata - e perversa - entre política e vida nua. Em tempos de política reduzida ao corpo-espécie e de declínio da experiência e da retórica, os tempos e espaços de alimentação na creche talvez não sejam muito mais do que uma expressão da ascensão daquela vida sem qualidades que caracteriza a violência da vitória do animal laborans.

\section{REFERÊNCIAS BIBLIOGRÁFICAS}

ADORNO, T. W. Educação e emancipação. 2. ed. São Paulo: Paz e Terra, 2000.

. Palavras e sinais: modelos críticos. 2. ed. Petrópolis: Vozes, 1995.

AGAMBEN, G. Homo sacer: o poder soberano e vida nua. Belo Horizonte: UFMG, 2004. 
ARENDT, H. A Condição humana. 10. ed. Rio de Janeiro: Forense Universitária, 2002.

BENJAMIN, W. Obras escolhidas,1: magia, técnica, arte e política. 4. ed. São Paulo: Brasiliense, 1993.

. Obras escolhidas, 2.: rua de mão única. 4. ed. São Paulo: Brasiliense, 2000.

BRASIL. Ministério da Saúde. Secretaria de Atenção à Saúde. Política nacional de alimentação e nutrição. 2. ed. rev. Brasília, 2003. (Série B: Textos básicos de saúde). Disponível em: <http://sisvan. datasus.gov.br/documentos>. Acesso em: 29 maio 2007.

DEL PRIORE, M. (Org.). História das crianças no Brasil. São Paulo: Contexto, 1999.

ELIAS, N. O Processo civilizador, 1: uma história dos costumes. Rio de Janeiro: Jorge Zahar, 1994. . o Processo civilizador, 2. Rio de Janeiro: Jorge Zahar, 1993.

GONDRA, J. G. A Sementeira do porvir: higiene e infância no século XIX. Educação e Pesquisa, São Paulo, v. 26, n.1, p. 99-117, jan./jun. 2000.

HORKHEIMER, M. Eclipse of reason. New York: Continuum, 1996.

HORKHEIMER, M; ADORNO, T. W. Dialética do esclarecimento: fragmentos filosóficos. Rio de Janeiro: Zahar, 1985.

PHILIPPI, S. T. et al. Pirâmide alimentar adaptada: guia para escolha dos alimentos. Revista de Nutrição, Campinas, v. 12, n. 1, p. 65-80, 1999.

SANT’ANNA, D. B. Bom para os olhos, bom para o estômago: o espetáculo contemporâneo da alimentação. Revista Pro-Posições, Campinas, SP, v. 14, n. 2, p. 41-52, maio/ago. 2003.

VALADÃO, M. M. Educação infantil e saúde: o estabelecimento de critérios de saúde para o funcionamento de instituições de educação infantil, 2. In: BRASIL. Ministério da Educação e do Desporto. Secretaria de Educação Fundamental. Subsídios para credenciamento e funcionamento de instituições de educação infantil. Brasília, 1998. p. 77-86.

ZUIN, A. A. S.; PUCCI, B.; OLIVEIRA, N. R. de. Adorno: o poder educativo do pensamento crítico. 2. ed. Petrópolis: Vozes, 2000.

\title{
ANA CRISTINA RICHTER
}

Doutoranda em Educação pela Universidade Federal do Paraná - Curitiba ana_tinaa@uol.com.br

\author{
ALEXANDRE FERNADEZ VAZ \\ Professor associado 1 do Centro do Programa de Pós-Graduação em \\ Educação, da Universidade Federal de Santa Catarina/Campus Trindade - \\ Florianópolis \\ alexfvaz@pq.cnpq.br
}

